Document downloaded from:

http://hdl.handle.net/10251/62940

This paper must be cited as:

Doménech Antich, EM.; Jiménez Belenguer, Al.; Amoros, JA.; Ferrús Pérez, MA.; Escriche Roberto, MI. (2015). Prevalence and antimicrobial resistance of Listeria monocytogenes and Salmonella strains isolated in ready-to-eat foods in Eastern Spain. Food Control. 47:120125. doi:10.1016/j.foodcont.2014.06.043.

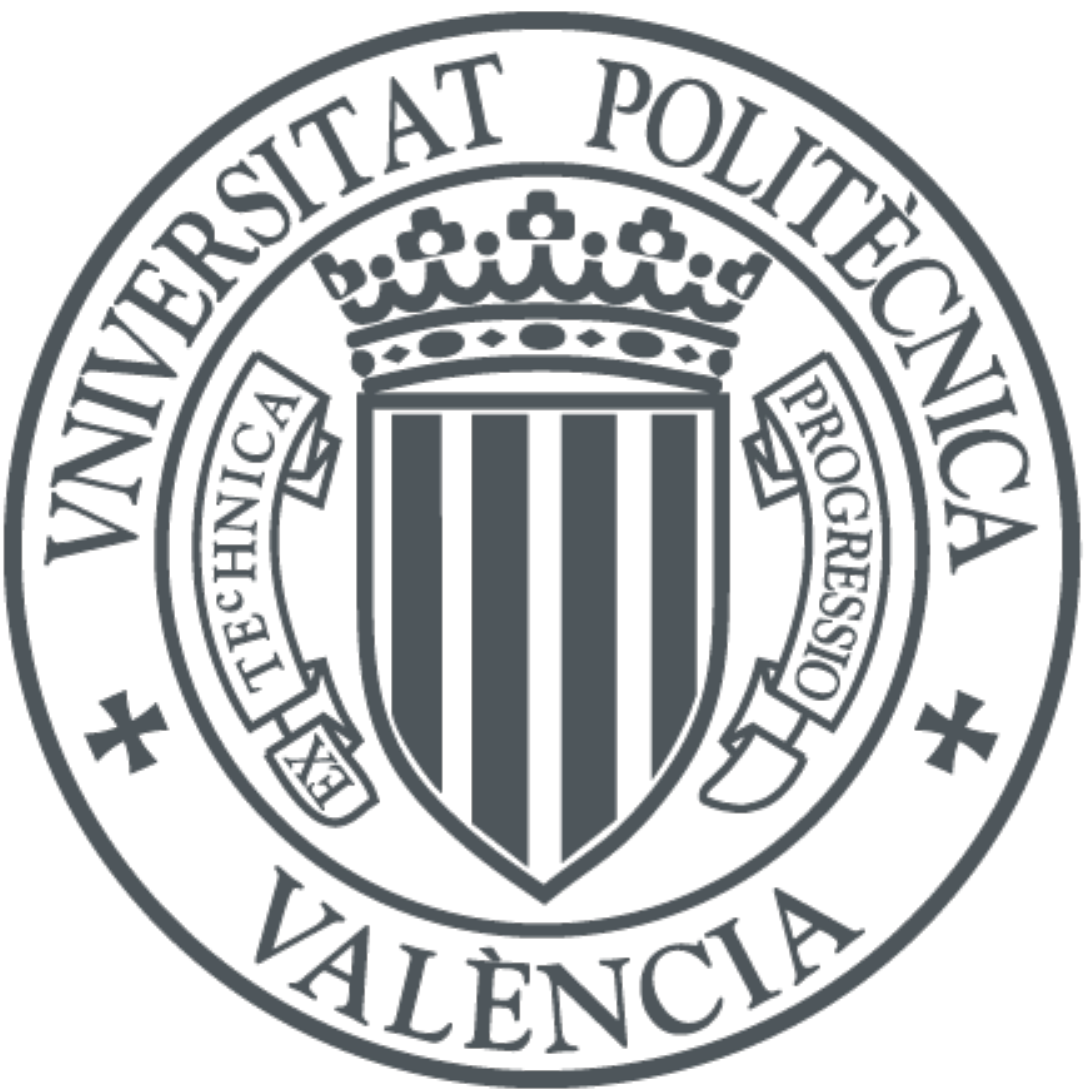

The final publication is available at

Copyright Elsevier

Additional Information 


\title{
Prevalence and antimicrobial resistance of $L$. monocytogenes and Salmonella strains isolated in ready-to-eat foods in Eastern Spain
}

\author{
Eva Doménech; Ana Jimenez-Belenguer; Jose Antonio Amoros; Maria Antonia Ferrus; \\ Isabel Escriche \\ Food control 47, (2015) 120-125
}

\begin{abstract}
Antimicrobial resistance is a major global public health concern and a food safety issue considered in the framework of Horizon 2020. Bearing this in mind, the current study determined the prevalence of $L$. monocytogenes and Salmonella strains isolated in ready-to-eat food sampled in industry and retail between 2006 and 2012 by the Official Food Control Services of the Valencian administration (Spain). The presence of L. monocytogenes was analysed in a total of 2864 samples including pasteurized cheese (624); cooked ham (487); dried pork sausages (192); ice cream (758) and smoked salmon (803). The presence of Salmonella was analysed in a total of 1264 samples: pasteurized cheese (289); cooked ham (316); dried pork sausages (78); ice cream (376) and smoked salmon (205). The results showed that $L$. monocytogenes was present in $3.8 \%$ of the samples, being most common in smoked salmon. Salmonella was not found in any of the products studied with the exception of 7 out 78 samples of dried pork sausage. Both L. monocytogenes and Salmonella showed resistance to 4 antimicrobials (ampicillin, cephalothin, tetracycline and trimethoprim-sulfamethoxazole). Moreover, the former was resistant to amikacin, ciprofloxacin, erythromycin and vancomycin while the later showed resistance to amoxicillinclavulanate and chloramphenicol. Furthermore, multi-resistance was found for both microorganisms.
\end{abstract}




\section{Introduction}

Listeria monocytogenes and Salmonella are pathogenic bacteria that can contaminate food products during or after processing. Neither of them are heat resistant and are therefore inactivated by industrial cooking. However, their presence in ready-to-eat food, which does not undergo any post-sale treatment to ensure its safety before consumption, implies a health threat for the consumer (Cabedo et al., 2008).

Listeriosis, caused by Listeria monocytogenes, is a disease that results in nearly 1600 illnesses each year in the United States with more than 1400 hospitalizations and 250 deaths (Scallan et al., 2011). In the European Union the number of confirmed cases of listeriosis in 2012 was 1642. The overall notification rate of listeriosis was 0.41 cases per 100,000 population and the case-fatality rate was $17.8 \%$ (EFSA \& ECDC, 2014). Listeriosis may cause either a serious invasive illness affecting children, pregnant women, the immunocompromised and the elderly, with symptoms like meningitis, encephalitis, septicaemia, or, in healthy adults, a noninvasive febrile gastroenteritis or/and influenzalike symptoms (Pesavento et al., 2010). To date, 13 serovars of L. monocytogenes have been identified: " $4 b$ " is responsible for the majority of human listeriosis cases, and serovar " $1 / 2 \mathrm{a}$ " is the most prevalent serovar in food (Jamali \& Thong, 2014).

Listeria monocytogenes is a foodborne pathogen widely distributed throughout the natural environment and is consequently found in many types of food products. The EFSA results, published in 2013 indicated that in the European Union the highest frequency of positive samples in ready-to-eat food was found in fish $(10.4 \%)$, followed by meat $(2.1 \%)$ and cheese $(0.5 \%)$ (EFSA, 2013). Higher values had been published by other authors since 2000 , for instance, $21 \%$ to $34.1 \%$ was found for smoked fish at retail, (Uyttendaele et al., 2009; Di Pinto et al., 2010; Doménech et al., 2012); 2.7\% to $8.5 \%$ in deli meat products (Garrido et al., 2009) and $12.5 \%$ to $16.9 \%$ in cooked ham and cured dried pork sausage respectively (Cabedo et al., 2008). In relation to cheese, the EFSA results for L. monocytogenes are in accordance with other published surveys ( 0 to $2 \%$ ) (Vitas et al., 2004; Manfreda et al., 2005; Doménech et al., 2013). These variations in the percentage of prevalence may be due to the intrinsic properties of the products, processing conditions and the conditions in the food chain.

Salmonella is also a well-known pathogen which has been implicated in a large number of outbreaks of foodborne disease. In fact, 91,034 human cases were confirmed in Europe in 2012 (EFSA \& ECDC, 2014), and 1 million people in the United States contract Salmonella each year, with an average of 19,000 hospitalizations and 380 deaths (Scallan et al., 2011). Most human Salmonella infections result in a self-limiting gastrointestinal illness characterized by diarrhea, fever and abdominal cramps which do not warrant antimicrobial therapy (Mølbak, 2005).

The discovery of antibiotics in the midtwentieth century revolutionised the management and treatment of bacterial infections. However, these gains are in serious jeopardy due to the increase in antibiotic resistance and the potential global spread of genes resistant to pathogenic bacteria (Sharma et al., 2014). In some European countries, resistance rates to a single antibiotic exceed 40$50 \%$. In fact, Antimicrobial Multiple Resistance (AMR) is estimated to cause some 25,000 deaths each year (UE 2011). Increasing global trade and travel favours the spread of antimicrobial resistance between countries and continents. Therefore, antimicrobial resistance is a global public health concern. Actions to address threats posed by antimicrobial resistance include programs to monitor antimicrobial resistant microbes throughout the food chain.

According to the European Commission, a co-ordinated research effort is required to amass more information related to resistance rates. With this aim in mind, one of the main goals of Horizon 2020 "Health, Demographic Change and Wellbeing", is the reduction of antibiotic resistance in the food chain. Therefore, the objective of this work was to investigate the prevalence of L. monocytogenes and Salmonella, obtained by the official control carried out by the Valencian administration on ready-to-eat food products (pasteurized cheese, cooked ham, dried pork sausage and smoked fish) and to determine the susceptibility of these microorganisms to different antimicrobial agents.

\section{Material and methods}

Sample collection

A survey on Listeria monocytogenes and Salmonella was carried out by the Official Food Control Services of the Department of Health of the Valencian administration between 2006 and 2012 with the aim of estimating the prevalence and antimicrobial resistance of both microorganisms in ready-to-eat foods. 
A total of 2864 samples were analysed for the presence of L. monocytogenes [pasteurized cheese (624); cooked ham (487); dried pork sausages (192); ice cream (758) and smoked salmon (803)] and 1264 for Salmonella [pasteurized cheese (289); cooked ham (316); dried pork sausages (78); ice cream (376) and smoked salmon (205)], table 1.

The number of samples, the place where these must be taken (industry or retail) and type of food products to be analyzed were determined by the Valencian health administration as part of the official control process. Two main aspects were taken into account, on one hand Regulation (EC) $882 / 2004$ and on the other hand, information about consumption, the risk related to the product, data from the Rapid Alert System for Food and Feed, and data collected in previous years.

Approximately $250 \mathrm{~g}$ of samples were stored in insulated containers at $-18^{\circ} \mathrm{C}$ for ice cream and $4{ }^{\circ} \mathrm{C}$ for the rest of the products and sent to the laboratory for analysis. The transport time was no more than one hour in any case. A record of the name of the company, the batch, expiry date, date of manufacture, storage conditions, etc., was generated in each case.

\section{Sample examination}

Samples were examined by official control laboratories, which are accredited following the standard ISO/IEC 17025:2005. This describes the general requirements for the competence of testing and calibration laboratories.

The detection of pathogens was performed following official methods: Salmonella spp. (ISO 6579:2002) and Listeria monocytogenes (ISO 11290-1:1996 and ISO 11290-2:1998).

\section{Antimicrobial susceptibility test}

Antimicrobial susceptibility testing of Listeria and Salmonella was performed by the disk diffusion method according to the CLSI guidelines (CLSI, 2012). Susceptibility to fourteen antibiotics, including those used to treat human listeriosis and salmonellosis, (Oxoid) was determined: amikacin (AK: $30 \mu \mathrm{g}$ ), ampicillin (AMP: 10 $\mu \mathrm{g}$ ), amoxicillinclavulanate (AMC: 20/10 $\mu \mathrm{g}$ ), sulfamethoxazole-trimethoprim (STX: $1.25 / 23.75 \mu \mathrm{g}$ ), ceftriaxone (CRO: 30 $\mu \mathrm{g}$ ), ciprofloxacin (CIP: $5 \mu \mathrm{g}$ ), chloramphenicol (C: $30 \mu \mathrm{g})$, kanamycin $(\mathrm{K}: 30 \mu \mathrm{g})$, gentamicin $(\mathrm{CN}$ : $10 \mu \mathrm{g}$ ), nalidixic acid (NAL: $30 \mu \mathrm{g}$ ), tetracycline (TE: $30 \mu \mathrm{g}$ ), cephalothin (KF: $30 \mu \mathrm{g}$ ), vancomycin (VA: $5 \mu \mathrm{g}$ ) and erythromycin (E: $15 \mu \mathrm{g})$. CRO and $\mathrm{K}$ were only tested on Salmonella strains and VA and E on Listeria strains. The antimicrobials used were grouped into three categories based on their importance in human medicine (Veterinary Drugs Directorate, 2005). The category I antimicrobials with high importance in human medicine are AMC, CRO, CIP and VA; category II antimicrobials are AK, AMP, CN, E, $\mathrm{K}, \mathrm{KF}, \mathrm{NAL}$ and SXT (moderate importance); category III antimicrobials are C, and TE (low importance). E. coli ATCC 25922 and Enterococcus faecalis ATCC 29212 were used as control strains.

The diameters of growth inhibition zones were measured and interpreted according to the breakpoints recommended by the CLSI for the various types of antibiotics, and the strains were classified as sensitive, intermediate (reduced susceptibility) or resistant. The resistant strains were confirmed by determining the minimum inhibitory concentrations (MIC) by gradedconcentration antibiotic strips (E-test $\mathrm{AB}$ Biodisk), the interpretation of results was made according to CLSI guidelines.

\section{Statistical analysis.}

Descriptive analyses of the data were undertaken using Statgraphics Centurion XVI.II (Statpoint Technologies, Inc. Warrenton, Virginia). Relative proportions were compared using the Chi-squared test $\left(\mathrm{X}^{2}\right)$ and Fisher's exact test. Also, comparisons of means were made. A probability value of less than $5 \%$ was deemed to be significant.

\section{Results}

This study determined the prevalence of $L$. monocytogenes and Salmonella isolated from ready to eat products (Table 1). $L$. monocytogenes was found in 109 out of 2864 analyzed samples, which represents $3.8 \%$. Prevalence in smoked salmon had the highest percentage: 69 out of 803 samples (8.6\%), followed by dried pork sausages, 12 out of 192 $(6.3 \%)$. A lower percentage was obtained for Salmonella $(0.5 \%)$, as a result of 7 out 1264 samples found in one only product, dried pork sausages. An important result was that all pasteurized cheese, cooked ham, ice cream and smoked salmon samples were negative for Salmonella. There was a non-significant difference between the prevalence and the microorganism, L. monocytogenes and Salmonella (p-value 0.3145) and the prevalence according the type of product (p-value 0.2258 ).

Overall $89 \% \quad(98 / 109)$ of the $L$. monocytogenes isolates were susceptible to all tested antimicrobials, which implies that $10 \%$ of strains were resistant. Resistance to amoxicillinclavulanate, chloramphenicol and gentamicin 
was not found in any L. monocytogenes strain. Moreover, no resistance was found in $L$. monocytogenes isolated in cooked ham.

Fig. 1 shows the susceptibility profiles of the four ready-to-eat products to the eleven antibiotics tested in this study. Pasteurized cheese had the highest percentage of resistance, $35.7 \%(5 / 14)$ : one sample of hard cheese, three of fresh cheese and one semi-hard cheese. Moreover, this product was resistant to 6 out of 11 antimicrobials tested. A total of 3 out of 14 isolates $(21 \%)$ were resistant to amikacin, cephalothin, tetracycline and vancomycin; $14.3 \%(2 / 14)$ to erythromycin and $7.1 \%(1 / 14)$ to ampicillin. Intermediate susceptibility was displayed in vancomycin $35.7 \%$ (5/14) followed by amoxicillin-clavulanate, ampicillin and cephalothin 7.1\% (1/14). Finally, all $L$. monocytogenes strains were sensitive to chloramphenicol, ciprofloxacin, gentamicin and trimethoprim-sulfamethoxazole.

A total of 10 out of $12(83.3 \%) L$. monocytogenes strains isolated in dried pork sausages were sensitive or showed an intermediate susceptibility. Resistance to amikacin and trimethoprim-sulfamethoxazole was concurrently present in $16.7 \%$ of samples (2/12) followed by tetracycline $8 \%(1 / 12)$.

L. monocytogenes in ice-cream showed sensitivity to 10 out of 11 antibiotics tested. Only 2 out 6 of L. monocytogenes isolates were resistant to ciprofloxacin $(28.6 \%)$. Also two of them had intermediate susceptibility to cephalothin $(28.6 \%)$.

Finally, smoked salmon had the lowest percentage of resistance, $1.4 \%(2 / 69)$ of the $L$. monocytogenes isolates. One of them was resistant to ampicillin and the other one to cephalothin. Intermediate susceptibility to vancomycin was found in $5.9 \%(4 / 69)$ of the isolates.

Differences between the resistance and type of antibiotic were not significant ( $p$-value 0.6953). However, differences between resistance and type of microorganism ( $\mathrm{p}$-value 0.0000 ) and type of product ( $p$-value 0.0137 ) were significant in both cases.

All of the Salmonella isolates were found in samples of dried pork sausages, and all of them were sensitive to amikacin, ceftriaxone, ciprofloxacin, gentamicin and kanamycin. Fig 2. shows the resistance rates to the different antibiotics tested. The Salmonella strains were most resistant to Tetracycline $85.7 \% \quad(6 / 7)$. Resistance to ampicillin, chloramphenicol and trimethoprim-sulfamethoxazole was found in $71.4 \%(5 / 7)$ of the isolates. The next was cephalothin, ineffective in four out seven cases (57.1\%). Finally, amoxicillin-clavulanate was ineffective in two out of seven isolates $(28.6 \%)$.
Table 2 shows the multiple antibiotic resistance pattern obtained for $L$. monocytogenes and Salmonella and the involved ready-to-eat products. A total of 11 out 109 samples $(10 \%)$ of all L. monocytogenes isolates showed resistance to at least one antimicrobial agent and 5 out of $109(4.6 \%)$ showed multidrug resistance. In relation to Salmonella, this percentage was quite high, $28.6 \%$, as a result of 2 isolates out of 7 which were multi-resistant.

\section{Discussion}

The results obtained showed that $L$. monocytogenes was detected in all the types of products analysed, with the highest percentage in smoked salmon $(8.6 \%)$ followed by dried pork sausages $(6.3 \%)$. The smoked salmon results are slightly lower than those found by Dauphin et al. (2001) who found $9.53 \%$ of $L$. monocytogenes in smoked salmon $(\mathrm{n}=141)$ and by Garrido et al., (2009) who reported 10.8\% $(n=11)$. The results found in the present study for dried pork sausages concur with Vitas et al., (2004).

In relation to cheese, a wide range of levels of L. monocytogenes have been reported by other authors: $6.3 \%$ in 195 samples of soft cheese and $4.4 \%$ in 45 samples of hard cheese (Rudolf and Scherer, 2001), 2.1\% in 1656 samples of Gorgonzola cheese (Manfreda, et al., 2005); and $20 \%$ in 10 samples of fresh soft cheese (Pesavento et al., 2010). This variation in the percentage of prevalence may be due to the type of cheese, intrinsically properties, use of thermal treatment, personal hygiene, cleaning procedures, ventilation and processing conditions.

In relation to cooked meat such as ham, values reported by Uyttendaele et al. (2009) were in accordance with the present study $(1.1 \%)$. However, around $12 \%$ was found by other authors (Van Coillie et al., 2004; Gilbert et al., 2009). Improper handling or ineffective maintenance of cutting equipment are often the main causes of increased contamination in these products, which can justify the differences between authors.

Finally, in the present study the lowest percentage of prevalence of L. monocytogenes was found in ice cream, with values similar to other authors, 0.4\%-1\% (Miettinen et al., 1999; Warke et al., 2000).

Considering Salmonella, the results of this study suggest a generally low prevalence of this microorganism in all analysed products, with the exception of dried pork sausages. Previous studies of ice cream and cheese reported levels 
of less than $0.1 \%$ or no isolation (Ortolani et al., 2010; EFSA \& ECDC 2014). Salmonella in meat preparations, intended to be eaten without any additional treatment, were reported by Cabedo et al., 2008 with $2 \%$ in cooked ham and $11.1 \%$ in cured dried pork sausage.

The first resistant strain of $L$. monocytogenes was isolated in 1988. Since then, resistant strains have been found in foodstuffs, food contact surfaces in the industry as well as in human samples (Gomez et al., 2014). In the present study, L. monocytogenes isolates in cooked ham, ice cream and smoked salmon were sensitive to amikacin. However, they were resistant in pasteurized cheese $(21.4 \%)$ and dried pork sausages (16.7\%). These findings were higher than those found by Arslam and Özdemir (2008) who reported only $4.3 \%$ resistance, although intermediate resistance reached 34\%. The same authors did not find resistance to amoxicillin-clavulanate, coinciding with this study. This result is positive as amoxicillin-clavulanate is one of the preferred antibiotics used to treat listeriosis (Gomez et al., 2014). The present study showed that in pasteurized cheese this microorganism had $7.1 \%$ resistance to ampicillin. However, in relation to this antibiotic, a huge variety of results have been found by other authors: Pesavento et al., (2010) obtained 20\% in raw meat and retail food. Higher percentages were obtained in dairy products by Rahini et al., 2010 (26.3\%) and Harakeh et al., 2009 (60\%) and in Malaysian ready-to-eat food (100\%). (Marian et al., (2012).

The high levels of $L$. monocytogenes resistance to ampicillin could be explained by the fact that it is a first choice antibiotic, which is widely used in listeriosis treatment for humans (Conter et al., 2009). On the other hand, all strains were susceptible to cloramphenicol. The same result was found by Marian et al (2012) in RTE foods. However, values around $10 \%$ were found by Arslam and Özdemir (2008), and Rahini et al., (2010). Ciprofloxacin resistance was found in 2 out 7 samples of ice cream $(28.6 \%)$. This result was quite similar to values reported by Rahini et al., (2010) (21.1\%), however Arslam and Özdemir (2008) found no resistance. All L. monocytogenes were susceptible to gentamicin, which agrees with previous studies (Arslan \& Özdemir, 2008; Conter et al., 2009 and Jamali, 2013). The high susceptibility of isolates to gentamicin may be due to the fact that this antimicrobial is not used anymore for therapeutic purposes in veterinary medicine nor as a growth promoter in conventional animal fattening (Harakeh et al., 2009). Resistance to erithromycin was only found in pasteurized cheese $(14.3 \%)$. Similar values were reported by Rahini et al., (2010) $(15.8 \%)$ and Jamali et al., (2013) (11.1\%). However, no resistance was found in cooked ham, dried pork sausages, ice cream and smoked salmon, which concurs with Conter et al., (2009) and Marian et al., (2012). In the present paper, resistance to cephalothin was found in pasteurized cheese (21.4\%) and smoked salmon (1.4\%). Similar values were reported by Pesavento et al., (2010) who found that 6 out of 40 samples were resistant $(15 \%)$ to cephalothin in raw and ready-to-eat foods at retail.

L. monocytogenes isolated in dried pork sausages was resistant to trimethoprimsulfamethoxazole; however, no resistance was found in the rest of the analysed products. These results have a great importance, since this antimicrobial agent is the second choice for treatment of listeriosis, especially in patients allergic to penicillins (Pesavento et al., 2010). The highest resistance to tetracycline was found in pasteurized cheese (21.4\%). Results from other authors present a huge variation in resistance to this antimicrobial in dairy products: 15.8\% (Rahini et al., 2010; 20\% (Harakeh et al., 2009) and overall 70\% (Jamali et al., 2013). These high differences could be due to widespread use of this antimicrobial, especially in farms. Finally, resistance to vancomycin was found in pasteurized cheese $(21.4 \%)$ and intermediate resistance in dried pork sausages $(8.3 \%)$ and smoked salmon (5.9\%). These percentages are lower than those found by Harakeh et al., (2009) (26.6\%), who consider that this percentage is worrying as vancomycin is considered the last therapeutic option to treat human Listeria infection. However, other authors found no resistance, or it was lower than $10 \%$ (Arslam and Özdemir, 2008; Conter et al., 2009; Pesavento et al., 2010; Rahini et al., 2010).

In the current study, resistance to amikacin, ceftriaxone, ciprofloxacin, gentamicin and kanamycin was not found in any Salmonella strain. Sensitivity to these antimicrobials has also been reported by others (CIPARS, 2011; NARMS, 2011). This is encouraging as ciprofloxacin is a drug used for treating salmonellosis in human patients (Aslam et al., 2012). On the contrary, the highest percentage of resistance was found for tetracyclines $(85.7 \%)$. This is important as they are used parentally to treat a range of infections including bacteria, mycoplasma, and some protozoa. However, this percentage is not unusual. Resistance to ampicillin, chloramphenicol, streptomycin, sulfonamides and tetracyclines has been frequently observed in Salmonella isolates with a variety of origins, 
varying between $23.5 \%$ and $83.1 \%$ (Van Boxstael 2012). These resistance levels are similar to those found in Salmonella strains from cases of salmonellosis in humans. In fact, resistance in human Salmonella isolates was high for ampicillin, tetracyclines and sulfonamides and was moderate for streptomycin and nalidixic acid. These are antimicrobials that are or have commonly been used for treatment in humans and animals. However, resistance to ciprofloxacin (widely used in human medicine), was relatively low (EFSA \& ECDC, 2013).

Multi-resistant strains, which may represent potential threats to human health, were only found in pasteurized cheese and dried pork sausages in this study. Comparing the findings here with prior research, multi-resistance was also found in ready-to-eat food by Conter et al. (2009) who reported that $3.30 \%$ of $L$. monocytogenes strains isolated from milk and dairy products were multi-resistant to 5 antibiotics. Pesavento et al. (2010) isolated $27.5 \%$ L. monocytogenes multi-resistant strains from raw meat and retail food.

A high percentage of resistance and multiresistance was obtained for the antimicrobials classified as being of "high" and "medium importance" in relation to human health, which can jeopardize the effectiveness of clinical treatments and increase the severity of diseases (Veterinary drugs directorate, 2005). This highlights the importance of continued surveillance and the usefulness of this information to take measures in the primary sector.

\section{Acknowledgment}

This study was performed with the collaboration of the General Direction of Public Health of the Valencian Government Health Department. However, the views expressed in this paper do not necessarily reflect the positions or policies of this Health Department. The authors are grateful to all the inspectors in the Public Health Department of the Valencian Regional Government who participated in the monitoring programme. They also thank the technicians of the Public Health Laboratory of the Valencian Regional Government.

\section{References}

Arslan, S., \& Özdemir, F. (2008). Prevalence and antimicrobial resistance of Listeria spp. in homemade white cheese. Food Control, 19, 360-363.

Aslam, M., Checkley, S., Avery, B., Chalmers, G., Bohaychuk, V., Gensler, G., ReidSmith, R., \& Boerlin, P. (2012).
Phenotypic and genetic characterization of antimicrobial resistance in Salmonella. Serovars isolated from retail meats in Alberta, Canada. Food Microbiology 32, 110-117.

Cabedo, L., Picart i Barrot, L., \& Teixidó i Canelles, A. (2008). Prevalence of Listeria monocytogenes and Salmonella in ready to eat food in Catalonia, Spain. Journal of Food Protection. 71, 855-859.

CIPARS. (2011) Government of Canada. Canadian Integrated Program for Antimicrobial Resistance Surveillance Antimicrobial Resistance Short Report. Public Health Agency of Canada, Guelph, Ontario, 2012. http://publications.gc.ca/collections/colle ction 2013/aspc-phac/HP2-4-2-2011eng.pdf (Accessed March 2014).

CLSI. (2012). Performance Standards for Antimicrobial Disk Susceptibility Test; Approved Standard-Eleventh edition. CLSI document M02-A11. Wayne, PA: Clinical and Laboratory Standards Institute.

Conter, M., D. Paludi, E., Zanardi, S., Ghidini, A., Vergara, \& Ianieri, A. (2009). Characterization of antimicrobial resistance of foodborne Listeria monocytogenes. International Journal of Food Microbiology, 128, 497-500.

Dauphin, G., Ragimbeau, C., \& Malle, P. (2001). Use of PFGE typing for tracing contamination with Listeria monocytogenes in three cold-smoked salmon processing plants. International Journal of Food Microbiology, 64, 5161.

Di Pinto, A., Novello, L., Montemurro, F., Bonerba, E., \& Tantillo, G. (2010). Occurrence of Listeria monocytogenes in ready-to-eat foods from supermarkets in southern Italy. New Microbiologica, 33, 249-252.

Doménech, E., Amorós, J.A., Martorell, S., \& Escriche, I. (2012). Safety assessment of smoked fish related to Listeria monocytogenes prevalence using risk management metrics. Food Control 25, 233-238.

Doménech, E., Amorós, J.A., \& Escriche, I. (2013). Effectiveness of prerequisites and the HACCP plan in the control of microbial contamination in ice cream and cheese companies. Foodborne Pathogens and Disease 10, 222-228.

EFSA. (2013). Analysis of the baseline survey on the prevalence of Listeria monocytogenes in certain ready-to-eat foods in the EU, 2010-2011 Part A: 
Listeria monocytogenes prevalence estimates Journal, 11(6):3241. http://www.efsa.europa.eu/en/efsajournal /pub/3241.htm. (Accessed March 2014).

EFSA \& ECDC. (2013). The European Union Summary Report on antimicrobial resistance in zoonotic and indicator bacteria from humans, animals and food in 2011. EFSA Journal, 11(5):3196. http://www.efsa.europa.eu/de/efsajournal /pub/3196.htm\#tabs-1 (Accessed March 2014).

EFSA \& ECDC. (2014). The European Union Summary Report on Trends and Sources of Zoonoses, Zoonotic Agents and Foodborne Outbreaks in 2012. EFSA Journal, 12(2):3547

http://www.efsa.europa.eu/en/efsajournal /pub/3547.htm (Accessed March 2014).

Garrido, V., Vitas, A.I., \& García-Jalón, I. (2009). Survey of Listeria monocytogenes in ready-to-eat products: Prevalence by brands and retail establishments for exposure assessment of listeriosis in Northern. Food Control, 20, 986-991.

Gilbert, S., Lake, R., Hudson, A., \& Cressey, P. (2009). Risk profile: Listeria monocytogenes in processed ready-to-eat meats.

http://www.foodsafety.govt.nz/elibrary/i ndustry/Risk_Profile_

Listeria_Monocytogenes_Processed-

Science_Research.pdf (Āccessed March 2014).

Gómez, D., Azón, E., Marco, N., Carramiñana, J.J., Rota, C., Ariño, A., \& Yangüela, J. (2014). Antimicrobial resistance of Listeria monocytogenes and Listeria innocua from meat products and meatprocessing environment. Food Microbiology, 42, 61-65.

Jamali, H., Radmehr, B., \& Thong, K.L. (2013). Prevalence, characterisation, and antimicrobial resistance of Listeria species and Listeria monocytogenes isolates from raw milk in farm bulk tanks. Food Control, 34, 121-125.

Jamali, H., \& Thong, K.L. (2014). Genotypic characterization and antimicrobial resistance of Listeria monocytogenes from ready-to-eat foods. $\cdot$ Food Control, 44, 1-6.

Harakeh, S., Imane, S., Omar, Z., Elias, B., Elie, B., \& Nisreen, A. (2009). Antimicrobial resistance of Listeria monocytogenes isolated from dairy-based food products. Science of the Total Environment, 407, 4022-4027.
Manfreda, G., De Cesare, A., Stella, S., Cozzi, M., \& Cantoni, C. (2005). Occurrence and ribotypes of Listeria monocytogenes in Gorgonzola cheeses. International Journal of Food Microbiology, 102, 287293.

Marian, M.N., Sharifah Aminah, S.M., Zuraini, M.I., Son, R., Maimunah, M., Lee, H.Y., Wong, W.C., \& Elexson, N. (2012). MPN-PCR detection and antimicrobial resistance of Listeria monocytogenes isolated from raw and ready-to-eat foods in Malaysia. Food Control, 28, 309-314.

Miettinen, M., Björkroth, K.J., \& Korkeala, H. (1999). Characterization of Listeria monocytogenes from an ice cream plant by serotyping and pulsed-field gel electrophoresis. International Journal of Food Microbiology,46, 187-192.

Mølbak, K. (2005). Human health consequences of antimicrobial drug-resistant Salmonella and other foodborne pathogens. Clinical Infectious Diseases, 41, 1613-1620.

NARMS. (2011). National Antimicrobial Resistance Monitoring System: Retail Meat Annual Report. http://www.fda.gov/downloads/AnimalV eterinary/SafetyHealth/AntimicrobialRes istance/NationalAntimicrobialResistance MonitoringSystem/UCM334834.pdf (accessed March 2014).

Ortolani, M.B.T., Moraes, P.M., Perin, L.M., Viçosa, G.N., Carvalho, K.G., Silva, A. J, \& Nero, L.A. (2010). Molecular identification of naturally occurring bacteriocinogenic and bacteriocinogeniclike lactic acid bacteria in raw milk and soft cheese. Journal of Dairy Science, 93, 2880-2886.

Pesavento, G., Ducci, B., Nieri, D., Comodo, N., \& Lo Nostro, A. (2010). Prevalence and antibiotic susceptibility of Listeria spp. isolated from raw meat and retail foods. Food Control, 21, 708-713.

Rahimi, E., Mehrdad, A., \& Hassan, M. (2010). Prevalence and antimicrobial resistance of Listeria species isolated from milk and dairy products in Iran. Food Control, 21, 1448-1452.

Regulation (EC) No 882/2004 of the European Parliament and of the Council of 29 April 2004 on official controls performed to ensure the verification of compliance with feed and food law, animal health and animal welfare rules (L 165, 30.4.2004, p. 1-141).

Rudolf, M., \& Scherer, S. (2001). High incidence of Listeria monocytogenes in European red smear cheese. 
International Journal of Food Microbiology 63, 91-98.

Sharma, P., Tomar, S.K., Goswami, P., Sangwan, V., \& Singh, R. (2014). Antibiotic resistance among commercially available probiotics. Food Research International, 57, 176-195.

Scallan, E., Hoekstra, R.M., Angulo, F.J., Tauxe, R.V., Widdowson, M.A., \& Roy, S.L. (2011). Foodborne illness acquired in the United States - major pathogens. Emerging Infectious Diseases, 17, 7-15.

UE. (2011). Commission staff working paper accompanying document to the commission recommendation on the research joint programming initiative 'the microbial challenge - an emerging threat to human health brussels, 27.10.2011 SEC(2011) 1295 final. http://era.gv.at/object/document/677/atta ch/CommRec DOCUMENTDETRAVA IL_f.pdf (accessed March 2014)

Uyttendaele, M., Busschaert, P., Valero, A., Geeraerd, A.H., Vermeulen, A., Jacxsens, L., Goh, K.K., De Loy, A., Van Impe, J.F., \& Devlieghere, F. (2009). Prevalence and challenge tests of Listeria monocytogenes in Belgian produced and retailed mayonnaise-based deli-salads, cooked meat products and smoked fish between 2005 and 2007. International Journal of Food Microbiology, 133, 94-104.

Van Boxstael, S., Dierick, K., Van Huffel, X., Uyttendael, M., Berkvens, D., Herman, L., Bertrand, S., Wildemauwe, C., Catry, B., Butaye, P., \& Imberechts, H. (2012). Comparison of antimicrobial resistance patterns and phage types of Salmonella Typhimurium isolated from pigs, pork and humans in Belgium between 2001 and 2006. Food Research International, $45,913-918$.

Van Coillie, E., Werbrouck, H., Heyndrickx, M., Herman, L., \& Rijpens, N. (2004). Prevalence and typing of Listeria monocytogenes in ready-to-eat food products on the Belgian market. Journal of Food Protection, 67, 2480-2487.

Veterinary Drugs Directorate. (2005). Proposed categorization of antimicrobial drugs. In: Current Thinking on Risk Management Measures to Address Antimicrobial Resistance Associated with the Use of Antimicrobial Agents in Food-producing Animals. http://www.hc-sc.gc.ca/dhpmps/alt_formats/hpfb-dgpsa/pdf/vet/amrram_rep-rap_06_05-eng.pdf (accessed March 2014).
Vitas, A.I., Aguado. V., \& Garcia-Jalon, I. (2004). Occurrence of Listeria monocytogenes in fresh and processed foods in Navarra (Spain). International Journal of Food Microbiology, 90, 349356.

Warke, R., Kamat, A., Kamat, M., \& Thomas, P. (2000). Incidence of pathogenic psychrotrophs in ice cream sold in some retail outlets in Mumbai, India. Food Control, 11, 77-83. 